\title{
COMPUTATIONAL ANALYSIS OF EFFECT OF STACKING ORIENTATION ON LOW VELOCITY IMPACT BEHAVIOR OF GFRP COMPOSITE LAMINATE
}

\author{
Chirangivee.K.R ${ }^{1}$, Harsha.S ${ }^{2}$, Akash.D.A ${ }^{3}$ \\ ${ }^{\text {I}}$ Postgraduate Student, Mechanical Engineering Department, Vijayavittala Institute of Technology, Karnataka, India \\ ${ }^{2}$ Professor, Mechanical Engineering Department, Vijayavittala Institute of Technology, Karnataka, India \\ ${ }^{3}$ Assistant Professor, Mechanical Engineering Department, Vidyavardhaka College of Engineering, Karnataka, India
}

\begin{abstract}
In recent years, Glass Fiber-reinforced plastic (GFRP) composite materials have been increasingly replacing conventional metallic materials in structural applications, due their excellent specific strength and stiffness properties. However, GFRP laminate having weak interfaces in normal to loading direction and they are very susceptible to impact loading. The damage of composite structures to impact events is one of the most important aspects of study to uncover the significance and the more dominant damage characteristics in terms of impactor mass, impact velocity, impact energy and different stacking orientations. This paper presents the effect of stacking sequence on low velocity impact behavior of GFRP composite laminate.
\end{abstract}

Keywords: Glass Fiber-reinforced plastic, stacking sequence, Specific Strength, impact velocity

\section{INTRODUCTION}

In recent years, Fiber-reinforced plastic (FRP) composite materials have been increasingly replacing conventional metallic materials in the aerospace, civil, marine, automotive industries, transportation and military structural applications, Since they offer excellent specific strength and stiffness properties. Composites' intrinsic high strength-to-weight and stiffness-to-weight ratios, corrosion and chemical resistance, improved impact and fatigue resistance and potential for lower fabrication and life-cycle costs are making them more attractive [1].

However, GFRP laminates have weak interfaces strength normal to loading direction and they are very susceptible for damage due to impact loading. Understanding the deformation and damage mechanisms involved in the impact of composite targets is important in the effective design of a composite structure, which if neglected may lead to catastrophic failure of the structure.

\subsection{Motivation}

Developing composites for specific applications such as impact resistance materials has been one of the challenges for engineers. Composites can be designed with different configurations for different applications. It is really expensive and time-consuming to develop composites and perform impact analysis experimentally and analytically.
FEA ( Finite Element Analysis )has been proven to be a powerful tool in analyzing various physical phenomena and a valuable aid to support in early stage of design process. Considering the time and cost of physical testing, FE technique offer the opportunity to develop a numerical model, which could accurately describe the impact and predict the complex internal damage mechanisms in a relatively short time.

After comprehensive literature survey it is clear that a little work can be found on numerical modeling of glass-fiber reinforced plastic composite for complete characterization of its dynamic behavior at low velocity. Hence FE code ABAQUS/Explicit software has been used for analyzing the deformation dynamic response of GFRP composite structure subjected to low velocity impact loading with the use of explicit time integration scheme.

\section{METHODOLOGY}

The methodology involved in modelling \& simulation to study the effect of stacking sequence on low velocity impact behaviour of GFRP composite laminate are as follows

- Comprehensive literature survey of different models; analytical models, experimental models \& numerical models used to model the low velocity impact of GFRP composite laminate.

- A mathematical formulation of GFRP composite laminate was made to describe the complete dynamic behavior under low velocity impact loading. 
- An Explicit FE model was formulated and simulated using Abaqus software to study the dynamic characteristics; contact force-time, stress-time, strain energy-time \& deflection-time of $[0 / 30 / 60 / 90]_{\text {s }}$ orientation for different impactor parametric variations.

- The same FE model was extended to study the dynamic behavior under different stacking orientations for different impactor parametric variations.

\subsection{Mathematical Formulation of Low Velocity}

\section{Impact Loading}

In the present study, deflections of the plate are assumed to be small in comparison to the dimensions of the plate and hence the small-deflection theory is found to be valid for the impact analysis. For small-strain theory, the equilibrium equation for a body in motion by neglecting the damping coefficient is written as

$$
[M]\{\ddot{U}\}+[K]\{U\}=\{F\}
$$

Where,

$[\mathrm{M}]$ is global mass matrix

$[\mathrm{K}]$ is stiffness matrix

$\{\mathrm{F}\}$ is external force vector

$\{\mathrm{U}\}$ and $\{\ddot{U}\}$ are the displacement and acceleration vectors In low-velocity impact, where the duration of impact is long in comparison to the period of the lowest mode of vibration of the plate, the Hertz contact law can be applied. In this case, Hertz theory which has been modified to apply for the case of impact on an anisotropic surface like composites is used to calculate the force caused by the impact on the plate. The Hertz contact law can be expressed as

$$
f=k \alpha^{3 / 2}
$$

\section{Where,}

$\mathrm{f}$ is the scalar contact force

$\alpha$ is the difference between the displacements of the centre of the nose of the impactor and that of the centre of the midsurface of the plate

$\mathrm{k}$ is modified Hertz constant which is given by

$$
k=\frac{4}{3} \sqrt{r} \frac{1}{\frac{1-\mu_{s}^{2}}{E_{s}}+\frac{1-\mu_{y x}^{2}}{E_{y y}}}
$$

Here, $r, \mu_{s}$ and $E_{S}$ are radius, Poisson's ratio and modulus of impactor, respectively. $\mathrm{E}_{\mathrm{yy}}$ is the transverse modulus normal to the fiber orientation in the upper-most composite layer.

\subsection{Explicit FE Modeling of Low Velocity Impact of GFRP Laminate}

Most popular finite element software, such as ANSYS and ABAQUS/Standard are developed with implicit integration methods. In implicit methods, all of the unknown variables are computed simultaneously at the same point in time. The advantage of this method over the explicit method is that it is unconditionally stable for linear, transient problems. Time steps that can be used with implicit integrators are much larger than those required for explicit methods.

Also the explicit method is conditionally stable; i.e. for the solution to be stable, the time step has to be small enough such that information does not propagate across more than one element per time step. A typical time step for explicit solutions is in the order of $10^{-3}$ to $10^{-6}$ seconds.

\subsection{Simulation of the Impact Model}

In this research work, the commercial Abaqus/Explicit code has been used to run the numerical FE model. The geometry of impactor and composite laminate is discussed in the following sections:

Table 1: Geometry of composite plate and impactor

\begin{tabular}{|c|c|c|}
\hline Object & Description & Value in $\mathbf{~ m m}$ \\
\hline \multirow{3}{*}{ Composite plate } & Length & 76.2 \\
\cline { 2 - 3 } & Breadth & 76.2 \\
\cline { 2 - 3 } & Thickness & 2.9 \\
\hline Impactor & Diameter & 10 \\
\hline
\end{tabular}

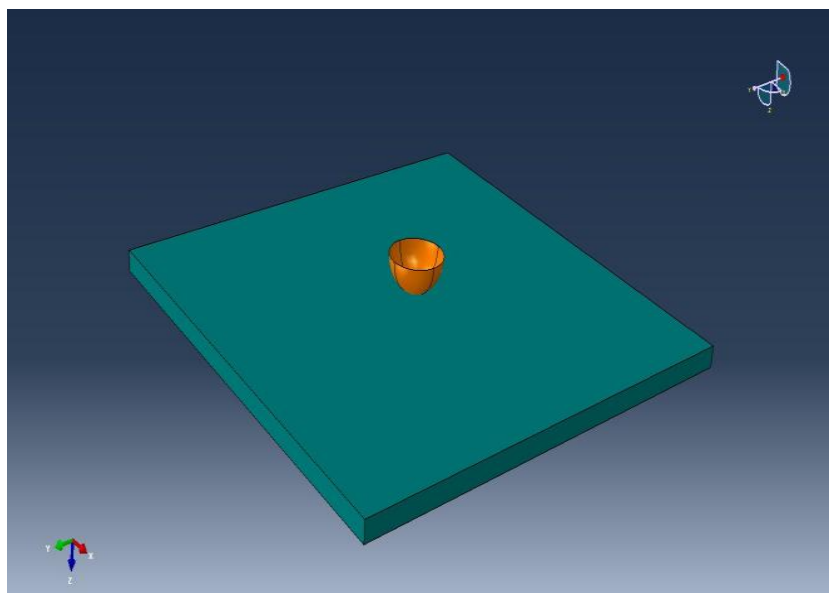

Fig. 1: Computational Geometry of GFRP Composite Plate and Impactor 


\subsection{Material Properties}

The mechanical properties of the composite GFRP lamina are given in Table 2. In Abaqus the properties of the lamina were assigned using *Elastic and type=LAMINA.

Table 2: Table Caption (TNR 10, Bold, Title Case)

\begin{tabular}{|l|l|}
\hline \multicolumn{1}{|c|}{ Property } & \multicolumn{1}{c|}{ Value } \\
\hline Longitudinal Modulus $\mathrm{E}_{11}$ & $40.5 \mathrm{Gpa}$ \\
\hline Transverse ModulusE $\mathrm{E}_{22}$ & $13.96 \mathrm{Gpa}$ \\
\hline In-plane Shear Modulus $\mathrm{G}_{12}$ & $3.1 \mathrm{Gpa}$ \\
\hline Out of plane Shear Modulus G13 & $3.1 \mathrm{Gpa}$ \\
\hline Out of plane Shear Modulus G23 & $5.0 \mathrm{Gpa}$ \\
\hline Poisson's ratio $\mu_{12}$ & 0.22 \\
\hline
\end{tabular}

\subsection{Composite Layup}

Glass Fiber-reinforced Laminate with 8 plies and each ply of $0.3625 \mathrm{~mm}$ thickness were considered. Figure. 2 shows stacking orientation and thickness details of the GFRP laminate of $[0 / 30 / 60 / 90]_{s}$ orientation.

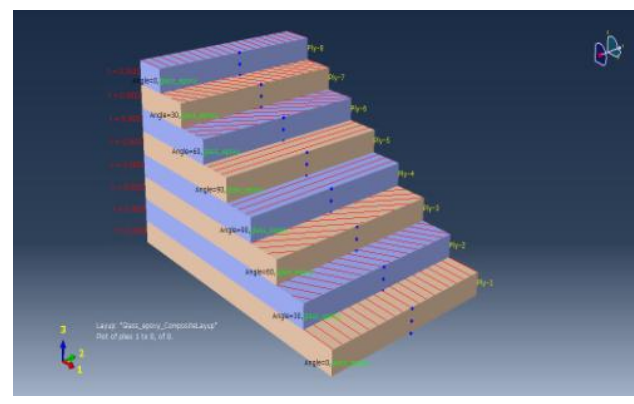

Fig. 2: Stacking orientation of the GFRP laminate

Here the plies of the composite laminate were created using 3D continuum shell elements SC8R, a general purpose linear quadrilateral shell element with reduced integration. The impactor was considered rigid and modeled using R3D4 and R3D3 elements. The reference node for the rigid impactor was defined at the bottom of the impactor. The mass of the impactor was assigned to the reference point of the projectile using *Mass. Figure 3 shows FE model of the Assembly

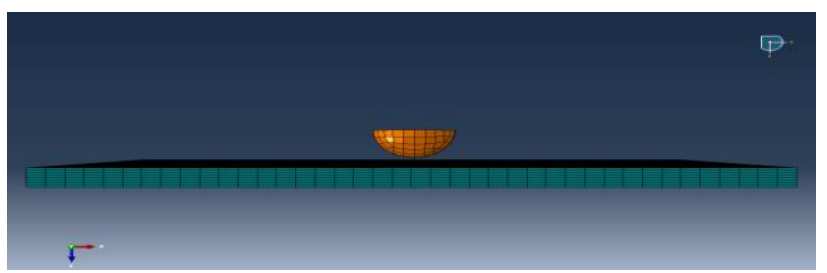

Fig.3: FE model of the Assembly

\subsection{Boundary and Initial conditions}

are arrested at the boundaries of the composite plate achieved by applying fixed boundary condition. All degrees of freedom of the reference point of the impactor were also constrained except U3, which allowed projectile motion in z-axis. The velocity of the impactor was defined at the reference point of the projectile using *Initial Conditions.

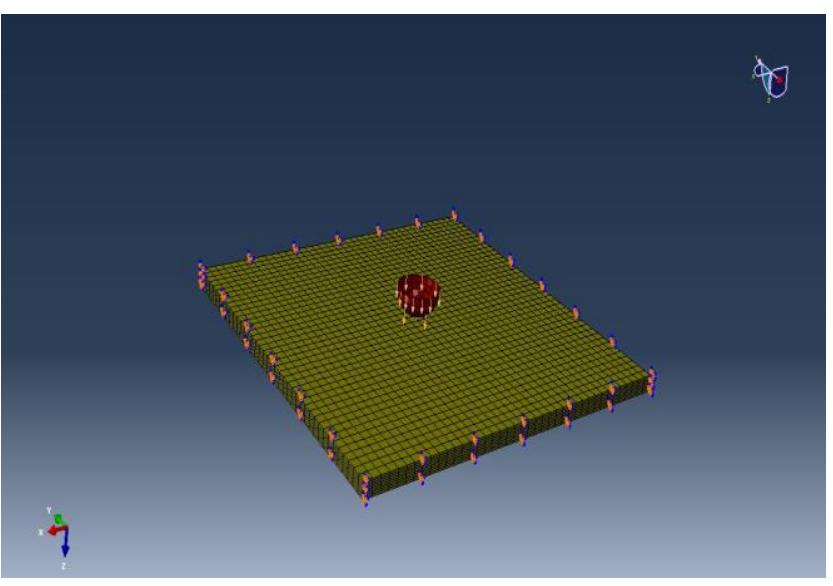

Fig.4: Boundary conditions and Initial conditions

\section{RESULTS AND DISCUSSION}

To study the effect of stacking orientation on different impact parameters in GFRP laminate composite, Simulations were conducted under three groups: equal impact energy, equal impactor mass and equal velocity for two different stacking sequences $\left[0^{\circ} / 30^{\circ} /-30^{\circ} / 90^{\circ}\right] \mathrm{s}$ and $\left[0^{\circ} / 75^{\circ} /-75^{\circ} / 90^{\circ}\right]$ s. The contour plots of Von-Mises stress, deflection of GFRP plate and contact force for $5 \mathrm{~kg} \_4 \mathrm{~m} / \mathrm{s} \_40 \mathrm{~J}$ case is shown below;

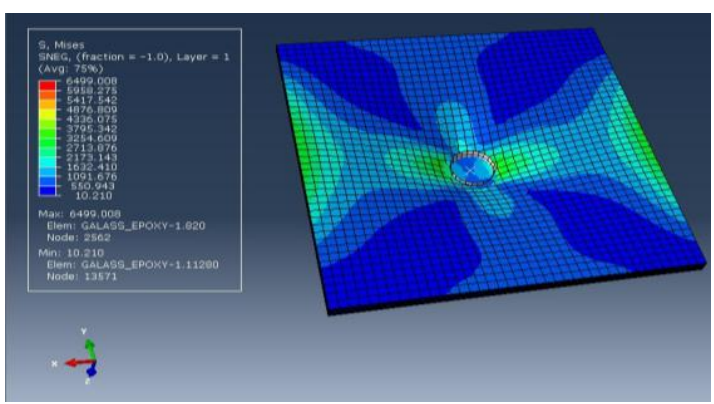

Fig 5: Contour plot of Von-Mises stress for $5 \mathrm{~kg} \_4 \mathrm{~m} / \mathrm{s}_{-} 40 \mathrm{~J}$ case 


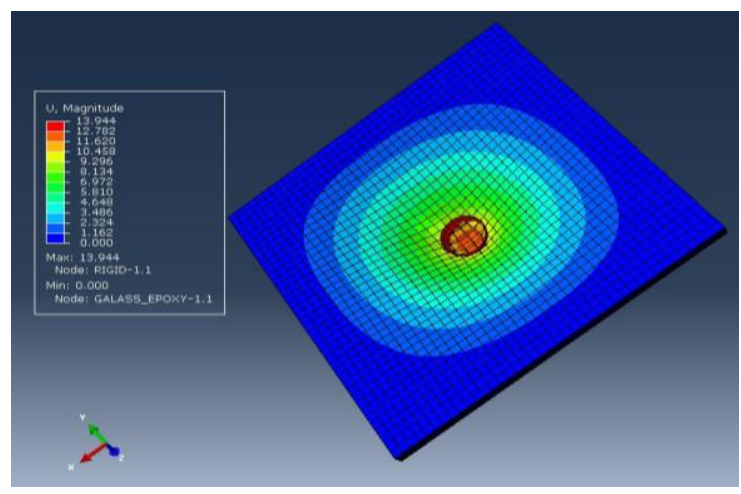

Fig 6: Contour plot of deflection of GFRP plate

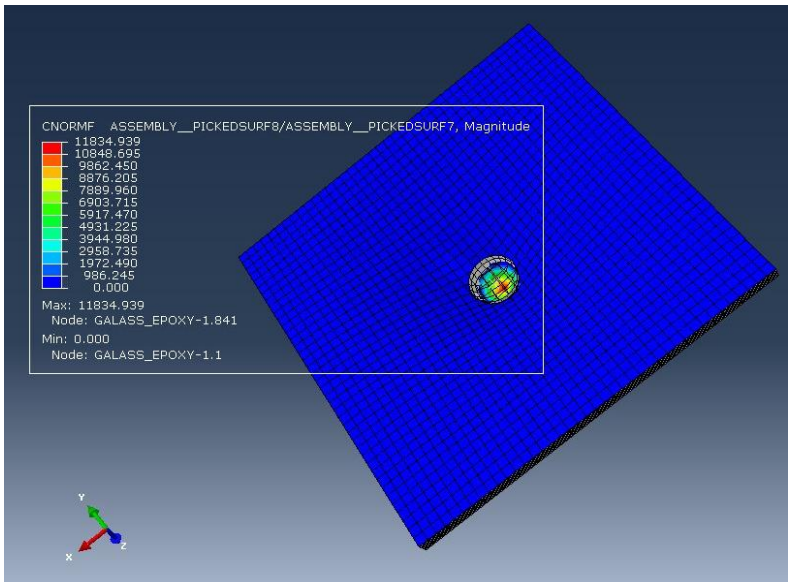

Fig 7: Contour plot of deflection of GFRP plate $5 \mathrm{~kg}$ _ $4 \mathrm{~m} / \mathrm{s} \_40 \mathrm{~J}$ case

The results are plotted analyze the effect of maximum contact force and impact mass on stacking sequence, at equal impact velocity.

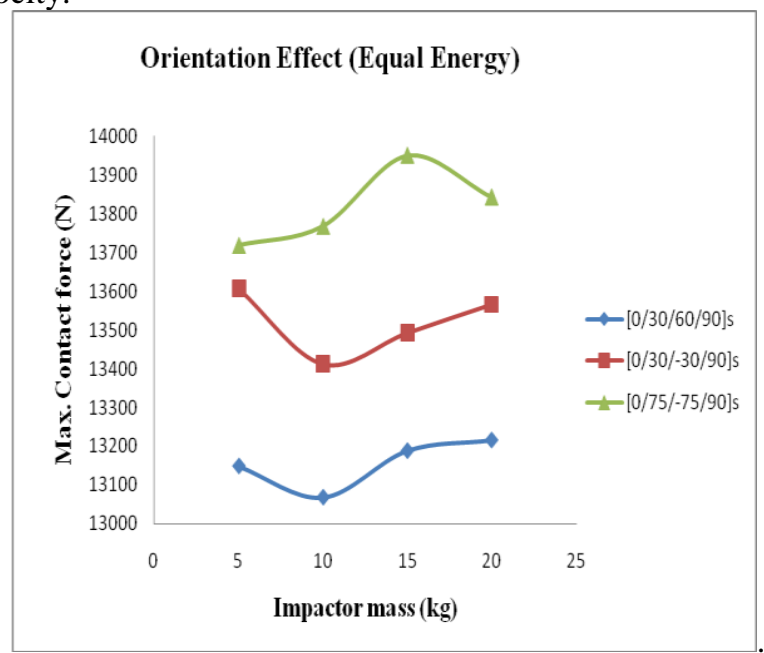

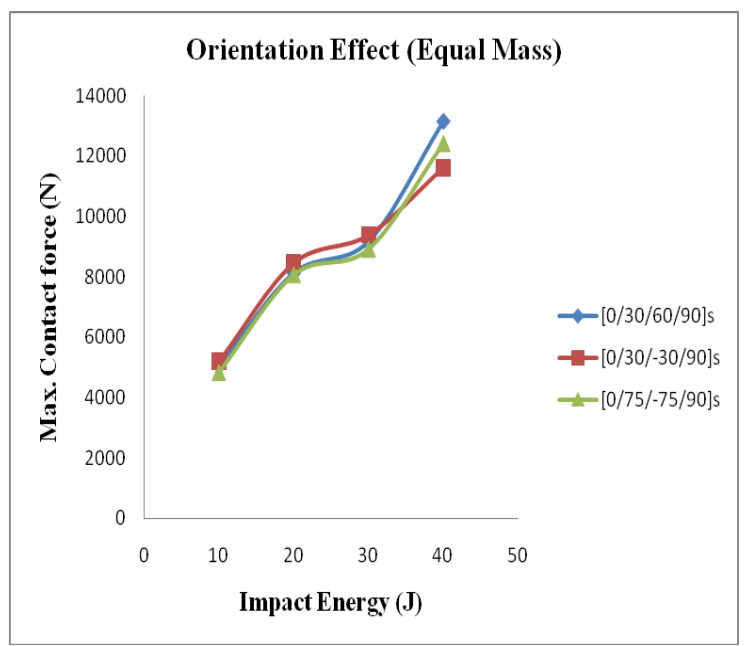

Fig 9: Orientation effect on max. contact force vs impactor mass at equal mass case

In Figure 8, it is clearly seen that, maximum contact force increases with increasing the difference between orientation angles for equal energy level (40 Joule). And it can also be seen that in Figure 9 the maximum contact force and deflection increase with impact energy.

\section{CONCLUSIONS}

Finite element code Abaqus/Explicit 6.10 was used effectively to simulate the low velocity impact of GFRP composite laminate plate. A geometric model of a $10 \mathrm{~mm}$ diameter rigid impactor and $76.2 \mathrm{~mm} \times 76.2 \mathrm{~mm} \times 2.9 \mathrm{~mm}$ Glass-fiber reinforced composite laminate of 8 plies was considered. The plies of the composite laminate were created using 3D continuum shell elements SC8R (12800). The impactor was considered rigid and modeled using R3D4 (102) and R3D3 (6) elements. Therefore,

a. It was observed from combined simulation results that, the maximum contact force changes linearly with increasing impact energy for the equal mass and the equal velocity.

b. For different stacking orientations, The maximum contact forces are obtained at $\left[0^{0} / 75^{0} /-75^{\circ} / 90^{0}\right]_{\mathrm{s}}$ orientation for constant impact energy due to the higher bending stiffness.

Thus the simulation model can be extended to predict the different failure analysis of composite which includes: delamination, matrix crack, matrix failure, and fiber failure, fiber crack using Hashin damage criterion and cohesive zone model in order to avoid the catastrophic failure of the laminate.

Fig 8: Orientation effect on max. contact force Vs impactor mass at equal energy case 


\section{REFERENCES}

[1] Soden P D, Kaddour A S, Hinton M J. "Recommendations for designers and researchers resulting from the world-wide failure exercise". Compos Sci Technol; Vol. 64, pp. 589-60, 2004.

[2] W.J. Cantwell and J.Morton, "Comparison of the Lowand High-velocity Impact Response of CFRP", Composites, Vol. 20(6), pp. 545-5551, 1989.

[3] K.N. Shivakumar, W. Elber, and W. Illg, "Prediction of Low-velocity Impact Damage in Thin Circular Laminates", American Institute of Aeronautics and Astronautics Journal, Vol. 23(3), pp. 442-449, 1985.

[4] P.O. Sjoblom, J.T. Hartness, and T.M. Cordell, "On Low-velocity Impact Testing of Composite Materials", Journal of Composite Materials, Vol. 22, pp. 30-52, 1988.

[5] D. Liu, and L.E. Malvern, "Matrix Cracking in Impacted Glass/epoxy Plates", Journal of Composite Materials, Vol. 21, pp. 594-609, 1987.

[6] S.P. Joshi, and C.T. Sun, "Impact-induced Fracture Initiation and Detailed Dynamic Stress Field in the Vicinity of Impact", Proceedings American Society of Composites 2nd Technical Conference, pp.177-185, 23-25 September 1987. 